\title{
EMENDAS CONSTITUCIONAIS E AÇÕES DIRETAS DE INCONSTITUCIONALIDADE NO BRASIL (1988-2016) // Antônio Alves
}

\section{Tôrres Fernandes ${ }^{1}$}

\section{Palavras-chave}

propostas de emenda à constituição / ações diretas de inconstitucionalidade / constituição brasileira

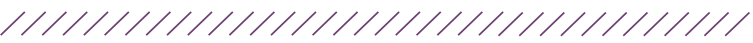

\section{Sumário}

1 Introdução

2 Constituições e rigidez constitucional

3 Controle de constitucionalidade e adi

4 Emenda constitucional

5 O que leva aos emendamentos à constituição?

6 Dados e métodos

7 Resultados

8 Conclusão

9 Referências

\section{Resumo}

O propósito deste trabalho é apresentar uma análise acerca das propostas de emenda à constituição (PEC) e Ações Diretas de Inconstitucionalidade (ADI) no período de 1988 até 2016. Metodologicamente, é utilizada estatística descritiva para verificar as PECS (propostas e promulgadas) e ADIs por ano. De acordo com os resultados, apesar da rigidez constitucional brasileira, foram realizados 95 emendamentos até 2016. 2014 foi o ano com maior quantidade de emendamentos (8). Em relação as Ações Diretas de Inconstitucionalidade, 2003 foi o ano com mais ADIs ajuizadas, enquanto que 2002 foi o ano com maior quantidade de julgamentos. 


\section{BRAZILIAN CONSTITUTIONAL AMENDMENTS AND DIRECT ACTIONS OF UNCONSTITUTIONALITY (1988-2016 // Antônio Alves Tôrres Fernandes ${ }^{2}$}

\section{Keywords}

proposals for amendment to the constitution / direct actions of unconstitutionality / Brazilian constitution

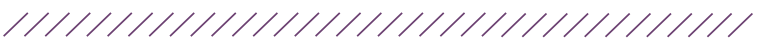

\begin{abstract}
The purpose of this paper is to present an analysis of the proposals for amendment to the constitution (PEC) and Direct Actions of Unconstitutionality (ADI) from 1988 to 2016. Methodologically, it was used descriptive statistics to verify the PECs and ADIs per year. According to the results, despite the Brazilian constitutional rigidity, 95 amendments were made until 2016. 2014 was the year with the highest number of amendments (8). In relation to Direct Actions of Unconstitutionality, 2003 was the year with more ADIs filed, while 2002 was the year with the highest number of judgments.
\end{abstract}

2 Graduated in Politics from Federal University of Pernambuco - UFPE, member of the group called 'Métodos de Pesquisa em Ciência Política' (DCP/UFPE) and e scholarship of scientific initiation from Foundation of Science and Technology Support of Pernambuco - FACEPE. 


\section{Introdução}

De acordo com Elster (2009), as constituições trazem em si a ideia de pré-compromissos, sendo escritas para evitar alguns problemas como o do desconto hiperbólico para combater possíveis interesses por parte dos parlamentares. Conforme Negretto (2012), as constituições são consideradas como "Lei maior", sendo estas desenhadas para manter um alto grau de preservação. Entretanto, as constituições podem ser modificadas por meio de alterações textuais, interpretação judicial, decisões executivas e legislativas e até mesmo a promulgação de uma nova Carta Magna. A discussão acerca das constituições também se refere à estabilidade ou instabilidade institucional. Ou seja, as constituições devem manter certo nível de estabilidade, mas também devem ser passíveis de adaptação à realidade vigente.

Este artigo busca analisar descritivamente as proposições de Ação Direta de Inconstitucionalidade e Propostas de Emenda à Constituição no período de 1988 a 2016. Verifico descritivamente as ADIs ${ }^{3}$ e PECs dado que são os mecanismos mais utilizados no tocante a alterações escritas (PEC) ou mudanças na interpretação (ADI) da Carta Magna. O artigo está dividido da seguinte maneira: primeiro, é feita uma apresentação acerca da rigidez constitucional, seguido de uma explanação acerca das Ações Diretas de Inconstitucionalidade e Propostas de Emenda à Constituição. Após isso, são apresentados os dados e métodos, resultados, conclusão e bibliografia.

\section{Constituições e rigidez constitucional}

A constituição é definida por Moraes (2014) como a lei fundamental e suprema de um Estado, sendo classificada por diversas características referentes ao seu conteúdo, forma, modo de elaboração, origem, estabilidade, extensão e finalidade. Em referência a rigidez, as constituições são classificadas como imutáveis, rígidas, flexíveis, semirrígidas e super-rígidas (MORAES, 2014). Conforme Brandão (2008), os fatores que incrementam o grau de rigidez de um sistema constitucional são: (1) a extensão, (2) abrangência, (3) o detalhamento da carta magna, bem como (4) a

3 As ADIs representam mais de 95\% das Ações de Controle de Constitucionalidade Ajuizadas no STF. dificuldade do processo de reforma constitucional. (BRANDÃO, 2008).

As constituições imutáveis são descritas como aquelas que não permitem nenhum tipo de alteração. As constituições rígidas são aquelas em que as alterações podem ser feitas por um processo legislativo mais dificultoso do que o relacionado às outras espécies normativas (MORAES, 2014). Constituições flexíveis são aquelas que, de acordo com Moraes (2014), podem ser alteradas por um processo legislativo ordinário. Mascarenhas (2008) classifica as constituições como semirrígidas quando algumas regras são alteradas pelo processo legislativo ordinário e outras regras só podem ser alteradas por um processo legislativo mais dificultoso.

Com base na classificação de rigidez constitucional apresentada acima, a Constituição Federal Brasileira de 1988 pode ser classificada como super-rígida (MORAES, 2014). Conforme Brandão (2008), a Carta Magna de 1988, possui um denso conteúdo normativo e moral ao mesmo tempo que adota um controle de constitucionalidade. Para outros autores, "a Constituição Brasileira seria um exemplo de Constituição super-rígida e rígida, concomitantemente" (TAVARES, 2013). Isso se deve ao fato de que, apesar da Constituição poder sofrer alterações por meio de um processo legislativo mais dificultoso (característica das constituições rígidas), existem alguns pontos que são imutáveis (cláusulas pétreas, $\mathrm{CF}$, art. $60 \S 4^{\circ}$ ).

Apesar do debate envolvendo a rigidez e flexibilidade das constituições, é necessário pontuar que ocorreu uma universalização das constituições rígidas, seguindo o modelo norte-americano (BRANDÃO, 2008). Com isso, a relação entre constituições flexíveis e rígidas não pode se tratar de uma relação excludente ou meramente dicotômica (BRANDÃO,2008). Ou seja, existe uma espécie de continuum entre a rigidez e a flexibilidade constitucional.

Além disso, a Constituição Brasileira também é classificada como analítica (MASCARENHAS, 2008)4. As constituições analíticas são aquelas que examinam

4 Mascarenhas (2008) classifica a Constituição Brasileira como formal, escrita, dogmática, promulgada, rígida e analítica. 
e regulamentam todos os assuntos relevantes à formação, destinação e funcionamento do Estado (MASCARENHAS, 2008). É diferente, por exemplo, da Constituição Americana, que é classificada como constituição sintética.

Apesar da rigidez constitucional na definição jurídica, o Brasil apresenta uma taxa de emendamento da Constituição acima dos outros países da América Latina. Ou seja, apesar da rigidez constitucional, existe uma alta intensidade no emprego dos métodos de alteração formal da constituição. Como pontuam Couto e Arantes (2006), o país ainda permanece em uma agenda constituinte e a consequência disso são as constantes alterações na carta magna. A natureza analítica da Constituição também leva a esse tipo de situação.

\section{Controle de constitucionalidade e adi}

De acordo com Moraes (2014), o Controle de constitucionalidade está ligado a supremacia da Constituição sobre o ordenamento jurídico. Mascarenhas (2008) pontua que o controle de constitucionalidade é a verificação da adequação de um ato jurídico à Constituição. Esse controle pode ser classificado como preventivo ou repressivo. $\mathrm{O}$ quadro abaixo apresenta os tipos de controle de constitucionalidade.

Quadro 1. Tipos de Controle de Constitucionalidade

\begin{tabular}{|l|l|}
\hline Tipo & Definição \\
\hline Controle Preventivo & \begin{tabular}{l} 
Ocorre antes ou durante o \\
processo legislativo, quando \\
busca impedir vigora criação \\
de uma lei ou ato normativo \\
inconstitucional (Masca- \\
renhas, 2008). É feito pelo \\
próprio Legislativo por meio \\
da Comissão de Constituição \\
e Justiça ou pela equipe de \\
Consultores Legislativos. \\
\hline Ocorre após a promulgação \\
do projeto de lei, ou seja, \\
quando a Lei passa a surtir \\
efeitos no Ordenamento \\
Jurídico. A verificação da \\
constitucionalidade das leis é \\
feita pela via judicial, através \\
do poder judiciário. (Mascare- \\
nhas, 2008)
\end{tabular} \\
\hline
\end{tabular}

\begin{tabular}{|c|c|}
\hline Repressivo difuso & $\begin{array}{l}\text { A arguição de inconstitucio- } \\
\text { nalidade de uma lei ou ato } \\
\text { normativo se dá dentro de } \\
\text { um processo judicial comum. } \\
\text { É feito por qualquer juiz, de } \\
\text { qualquer instância jurisdicio- } \\
\text { nal (Mascarenhas, 2008). Os } \\
\text { efeitos das decisões são inter } \\
\text { partes. }\end{array}$ \\
\hline Repressivo concentrado & $\begin{array}{l}\text { É processado exclusivamente } \\
\text { pelo STF, por meio da ação } \\
\text { direta de inconstitucionalida- } \\
\text { de, da ação declaratória de } \\
\text { constitucionalidade e pela ar- } \\
\text { guição de descumprimento de } \\
\text { preceito fundamental (Masca- } \\
\text { renhas, 2008). Os efeitos das } \\
\text { decisões são erga omnes. }\end{array}$ \\
\hline
\end{tabular}

Fonte: elaborado pelo próprio autor com informações ipsis litteris de Mascarenhas (2008).

Um dos dispositivos do controle de constitucionalidade no Brasil é a Ação Direta de Inconstitucionalidade (ADI). A ADI tem por objetivo principal declarar a inconstitucionalidade de uma norma no sentido material, de nível federal ou estadual (MASCARENHAS, 2008). Akerman (2012) afirma que a ADI tem por finalidade declarar a inconstitucionalidade de lei ou ato normativo estadual ou federal por vício de norma, material ou dupla inconstitucionalidade. A ADI faz parte do que Noronha (2011) coloca como mudança constitucional por interpretação judicial ${ }^{5}$. Ou seja, a Ação Direta de Inconstitucionalidade é instrumento que pode levar a uma nova interpretação do texto constitucional. De acordo com Brandão (2008), a distinção mais adequada em relação as mudanças constitucionais é que as emendas constitucionais podem alterar ou revogar efetivamente um dispositivo constitucional enquanto que a atualização da constituição pelo judiciário é limitada pelo próprio texto constitucional (limitação semântica) (BRANDÃO, 2008).

De acordo com o art. 103 da Constituição Federal de 1988, podem propor Ação Direta de Inconstitucionalidade o (1) Presidente da República, (2) Mesa do Senado Federal, (3) Mesa da Câmara dos Deputados, (4) Mesa de Assembleia Legislativa, (5) Câmara Legis-

5 Sendo o limite da interpretação de um dispositivo constitucional o limite semântico do texto constitucional. (BRANDÃO, 2008). 
lativa do Distrito Federal, (6) Governador de Estado, (7) Governador Distrital, (8) Procurador-Geral da República, (9) Conselho Federal da OAB, (10) partido político com representação no Congresso Nacional e (11) confederação sindical ou entidade de classe de âmbito nacional.

\section{$4 \quad$ Emenda constitucional}

Um dos instrumentos para alterar a constituição é a emenda constitucional. Como colocam Oliveira et al (2005), "a emenda constitucional caracteriza-se pela mudança das normas constitucionais mediante um processo legislativo especial, solene e mais dificultoso em relação as normas ordinárias”. Elster (2009) pontua alguns mecanismos que servem como obstáculos as emendas constitucionais: petrificação absoluta de dispositivos, adoção de maioria qualificada no parlamento, exigência de quórum maior do que para uma legislação ordinária, ratificação por Estados, por referendos e atrasos.

O artigo 59 da Constituição Federal de 1988 coloca a emenda à constituição como parte do processo legislativo. A Carta Magna pode ser emendada por meio de proposta do poder executivo, de no mínimo $1 / 3$ dos membros da Câmara dos Deputados ou Senado ou mediante manifestação da maioria relativa dos membros de mais da metade das Assembleias Legislativas (Art. 60, CF 1988).

No caso do Brasil, uma emenda à constituição é primeiramente analisada pela Comissão de Constituição e Justiça (CCJ) para verificação da constitucionalidade, legalidade e técnica legislativa da proposta. Após a aprovação na CCJ, é criada uma comissão especial que possui o prazo de 40 sessões do plenário para discussão específica do conteúdo da proposta e elaboração de parecer. Após isso, a PEC deve ser aprovada por $3 / 5$ de cada casa legislativa em duas votações separadas ${ }^{6}$. Quando a PEC é recebida na outra casa legislativa, também passa pela CCJ desta casa. Caso o texto não sofra nenhuma alteração na outra casa, a PEC é promulgada em sessão do Congresso

6 Para mais informações sobre o processo de tramitação de uma PEC visitar: http://www2.camara.leg.br/camaranoticias/noticias/70153.html . Acessado em 29/05/2017
Nacional, caso contrário, o texto volta para a casa de origem para nova votação.

\section{$5 \quad 0$ que leva aos emendamentos à constiuição?}

Dado que a Constituição Brasileira é classificada como rígida e até por alguns juristas como super-rígida, é de se esperar que a Carta Magna sofra poucas alterações. Entretanto, comparativamente, a Carta Magna Brasileira apresenta uma das menores taxas de rigidez constitucional da América Latina (MELO, 2013). Com isso, a Constituição Federal sofreu alterações diversas vezes ao longo do tempo, apresentando uma das maiores taxas de emendamento do mundo (MELO, 2013). O gráfico abaixo mostra a média da taxa de emendamento na última constituição de cada país da américa latina analisado por Negretto (2012). até 2008

Gráfico 1. Média da taxa de emendamento da última constituição de cada país analisado por Negretto (2012) (até 2008)

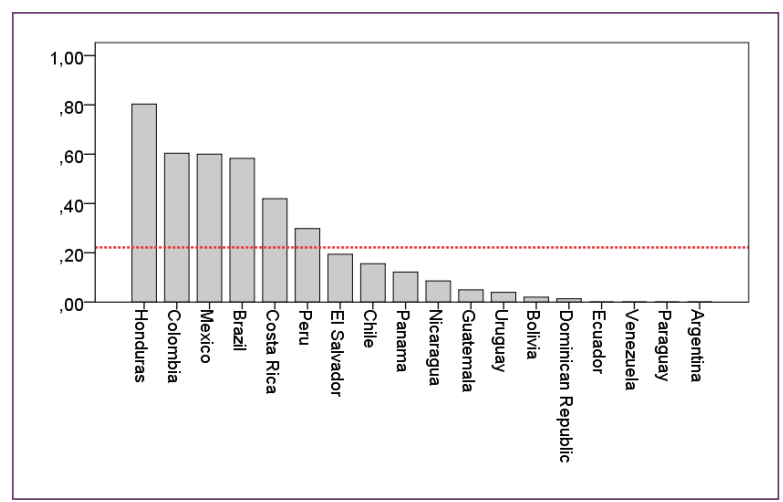

Fonte: Elaborado pelo próprio autor com base nos dados de Negretto (2012).

Conforme da Cruz et al (2004), a constituição não pode ser totalmente petrificada, cabendo à interpretação a garantia de funcionalidade da carta magna, adequando essa à realidade vigente. Além da interpretação do texto constitucional, realizado pelo judiciário, as emendas visam a alteração do próprio texto, sendo classificadas como emendamento formal (NORONHA, 2011).

Couto e Arantes (2006) pontuam que a constituição brasileira apresenta um grande número de políticas 
públicas e por isso está em processo permanente de mudança constitucional. Com base nisso, a Constituição apresenta diversas políticas de características mutáveis de governo a governo na própria carta constitucional, o que leva a um processo permanente de emendamentos. Para os autores, o Brasil apresenta uma característica singular quando a Constituição vincula os interesses do próprio governo a mudanças na constituição, sendo a agenda governamental na maioria das vezes, uma agenda também constituinte.

Devido a extensão da constituição brasileira, que acaba possuindo políticas constituintes e ordinárias, existe sempre uma necessidade de formação de ampla coalização por parte do governo vencedor para alterar a constituição em relação a determinadas matérias (BRANDÃO, 2008). Isso reduz, de acordo com Brandão (2008), o espaço para um maior pluralismo político.

Melo (2007) aponta que o executivo, a partir dos seus poderes e capacidade de formar coalizões, permite superar a ideia de constituição rígida, conseguindo, por meio de uma forte coalização no congresso, passar as reformas propostas. Para Melo (2013), o padrão de constantes emendamentos é resultado de uma constituição detalhada e regras de emendamento permissíveis. A constitucionalização de dispositivos, o que leva a uma constituição detalhada, seria resultado do processo constituinte, carregado de incertezas em relação ao futuro (MELO, 2013). Porém, como o próprio Melo (2013) coloca, a alta taxa de emendamento a constituição não significou alterações no conteúdo substantivo da Carta Magna ${ }^{7}$. Mudanças profundas no texto constitucional aconteceram em maior parcela apenas no período em que Fernando Henrique Cardoso era Presidente da República (FHC) $\mathrm{C}$, com mais de 30 propostas de emenda à constituição por parte do executivo (MELO, 2013).

Ao analisar o processo legislativo e emendamento constitucional no Brasil após 1988, Noronha (2011) identifica que o executivo é responsável apenas

7 Ao enfatizar o caráter 'casuístico e prolixo' da constituição, Brandão (2008), coloca como exemplo a emenda constitucional n. 51, referente ao provimento de agentes comunitários de saúde e agentes de controle de endemias que ingressaram no serviço público sem o cumprimento da regra constitucional da obrigatoriedade de concurso público (art. 37, II, CF/88) (BRANDÃO, 2008) por $5 \%$ do que consta nas emendas constitucionais aprovadas entre 1988 e 2010, o que evidencia uma preponderância do legislativo sobre o executivo nesse aspecto. De acordo com os achados de Noronha (2011), as propostas de emenda à constituição crescem ao longo do processo legislativo, sendo boa parte das alterações relativas a mudanças ou adição de novos dispositivos à carta constitucional, em vez de exclusão. Para o autor, a combinação envolvendo heterogeneidade parlamentar e procedimento de emendamento qualificado para alterar a constituição pode ter contribuído para um aumento substancial na quantidade de emendamentos (NORONHA, 2011).

\section{Dados e métodos}

Para apresentar descritivamente a quantidade de ADIs e PECs será utilizado o banco de dados da Câmara dos Deputados referente às propostas de emenda à constituição de 1988 até 2016 e o banco de dados disponibilizado por Mariano (2017) referente às Ações Diretas de Inconstitucionalidade apresentadas ao Supremo Tribunal Federal. Será utilizada estatística descritiva para analisar os resultados. 0 recorte temporal é de 1988 até 2016. O software utilizado para as análises foi o SPSS v. 22.

No que se refere as propostas de emenda à constituição, a contagem de PECs promulgadas será contabilizada como um todo e não pela contagem de dispositivos como proposto por Arantes e Couto (2006). Ou seja, será verificado, apenas a quantidade de emendas promulgadas, e não os dispositivos (polity e policies) modificados por meio do emendamento. Para garantir uma replicabilidade e transparência nos resultados (KING, 1995), os dados estão disponíveis na plataforma OSF8.

\section{Resultados}

O gráfico 2 apresenta a quantidade de Propostas de Emenda à Constituição apresentadas no período analisado:

8 Open Science Framework (OSF). Link para acesso: osf.io/79v2e 


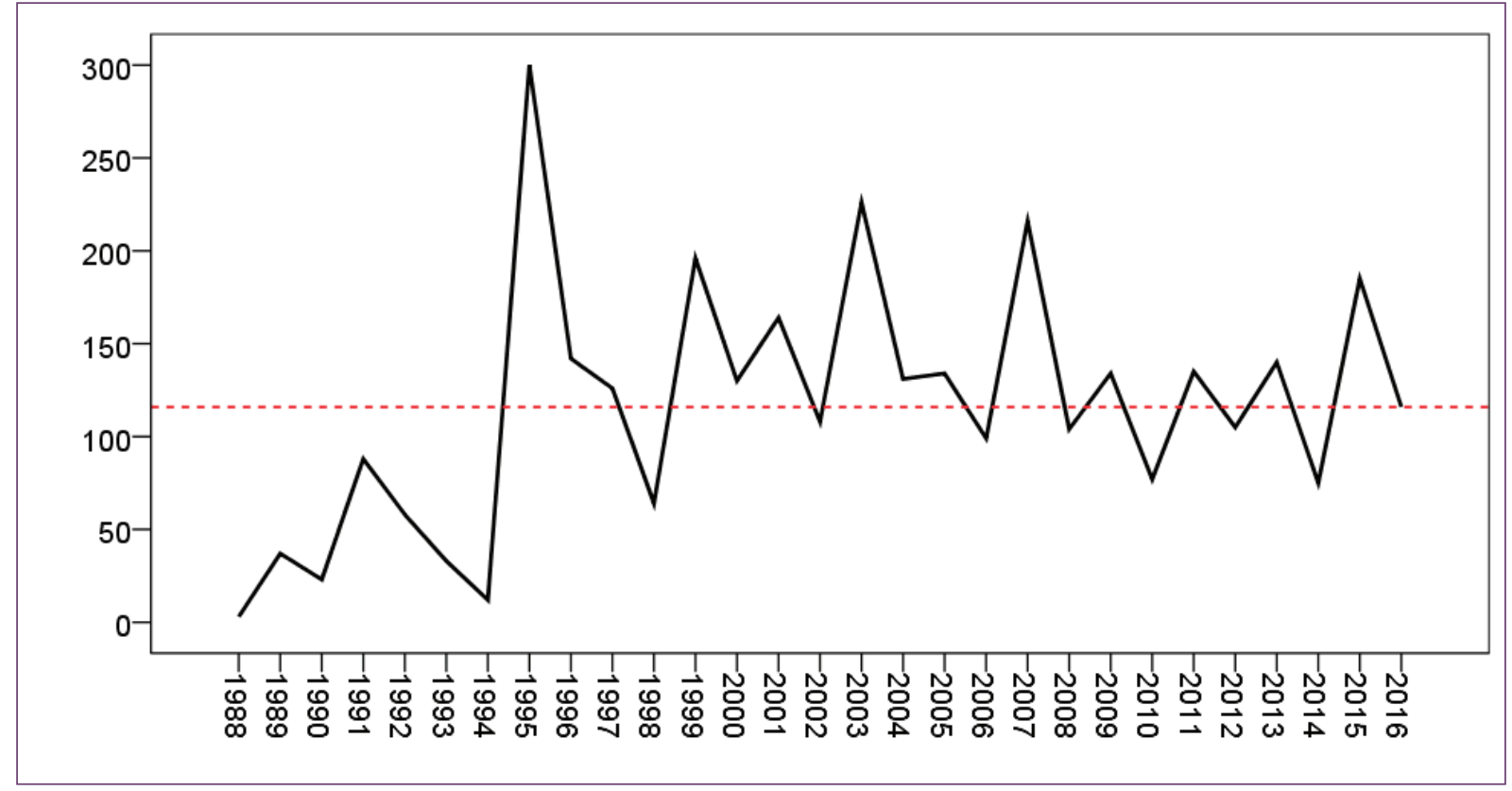

Fonte: Elaborado pelo próprio autor (2017)

Gráfico 3. PECs transformadas em norma jurídica no período analisado (1988-2016)

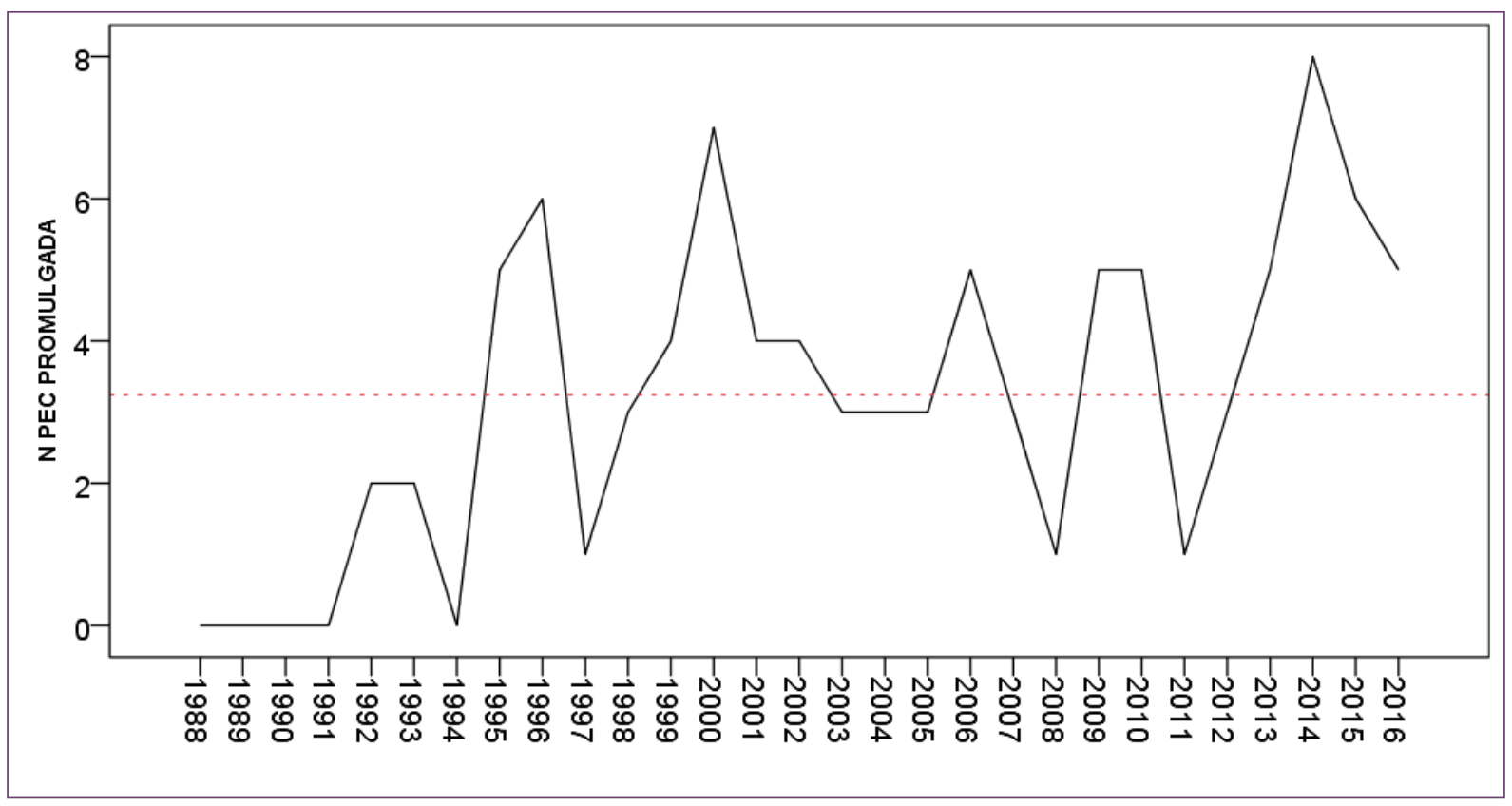

Fonte: Elaborado pelo próprio autor (2017)

A média de PECs propostas no período (115) está representada pela linha pontilhada vermelha. Percebe-se que não existe um "padrão" em relação à quantidade de PECs propostas por ano. A maior quantidade de PECs apresentadas no período está no ano de 1995, com 300 propostas de emenda à constituição. É possível perceber que, no primeiro ano de cada governo existe um aumento na quantidade de PECs. Os picos do gráfico estão em $1995\left(1^{\circ}\right.$ ano do governo FHC), 1999 ( $1^{\circ}$ ano do segundo mandato de FHC), 2003 ( $1^{\circ}$ ano do governo Lula) e 2007 ( $1^{\circ}$ do segundo mandato de Lula). A exceção fica com os primeiros anos dos mandatos do governo Dilma $(2010,2014)$. 


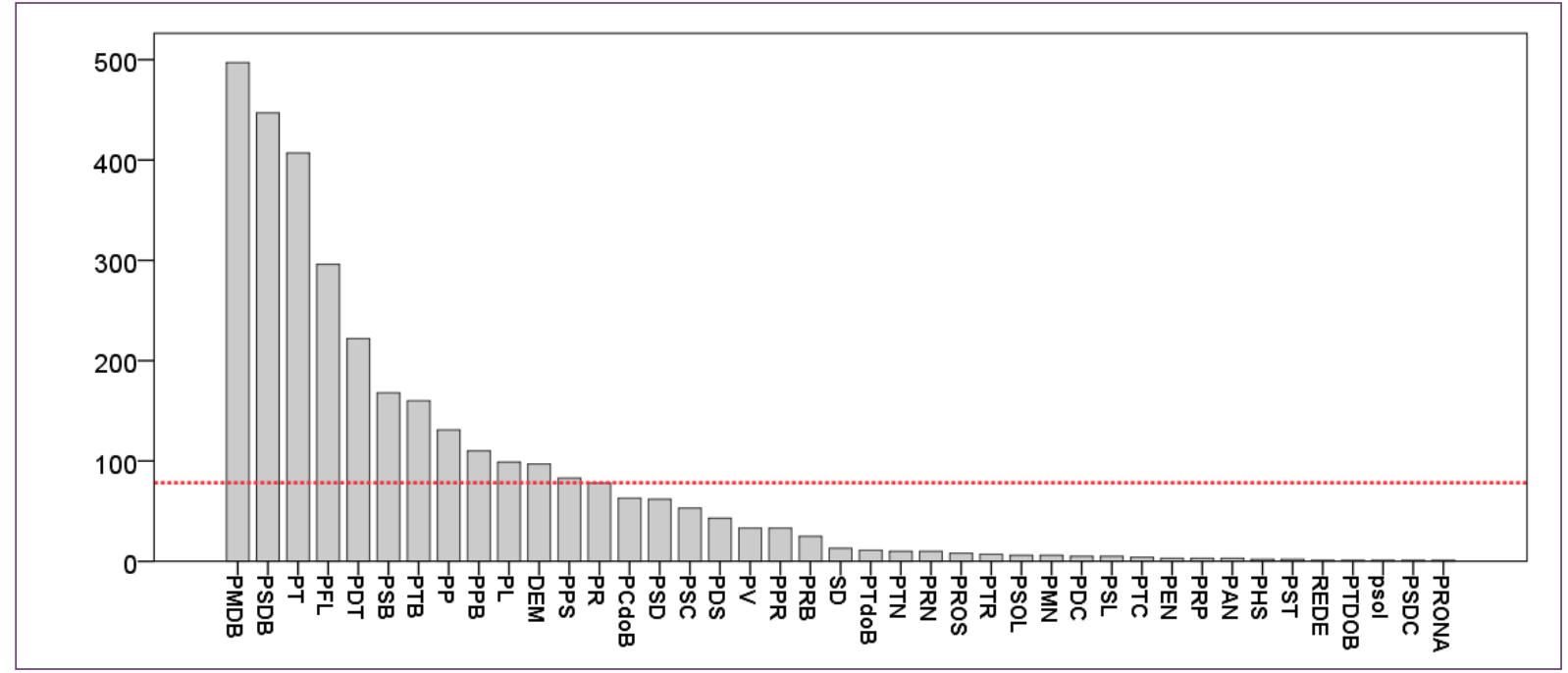

Fonte: Elaborado pelo próprio autor (2017)

Gráfico 5. Propostas de PEC pelo poder executivo (1988-2016)

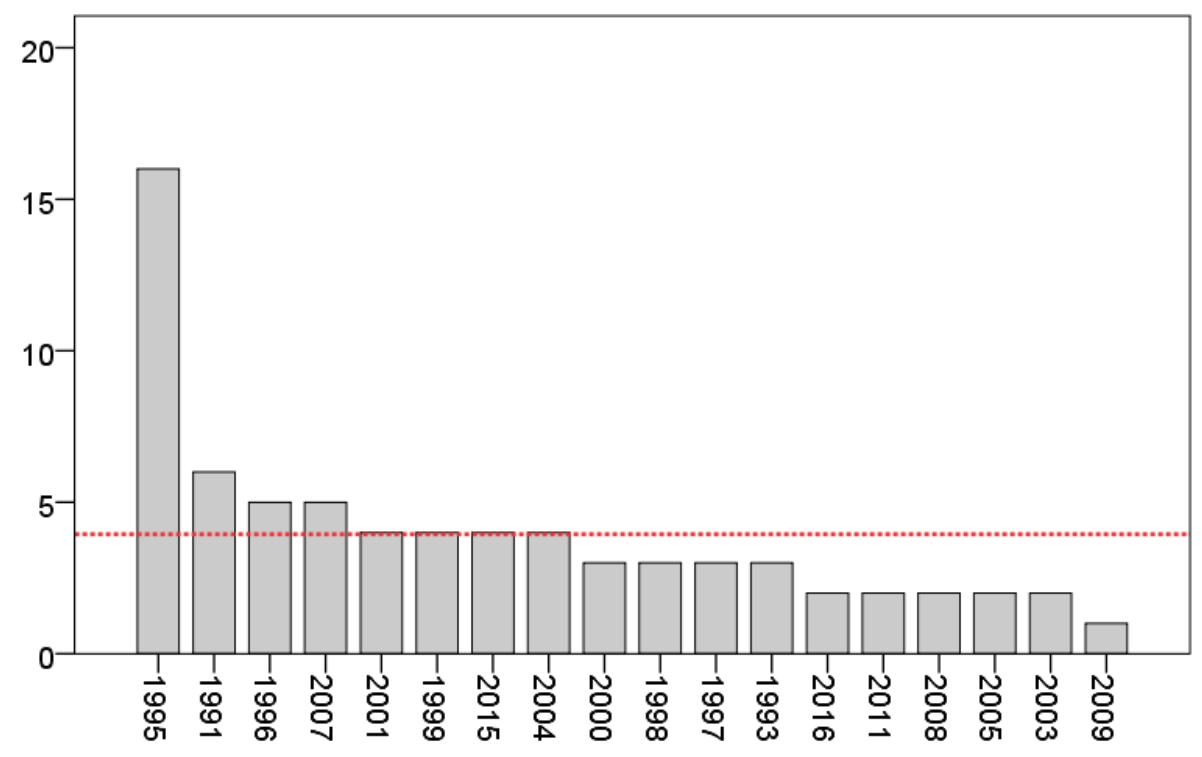

Fonte: Elaborado pelo próprio autor (2017)

Isso poderia acontecer devido ao argumento colocado por Couto e Arantes (2006) de que a agenda governamental está ligada diretamente a mudanças na constituição. Entretanto, ao se verificar os partidos que apresentaram as propostas nesses anos, percebe-se que em 1995 (44) e em 1999 (37) o partido que apresentou mais propostas foi o PFL, em 2003 foi o PMDB (45) e em 2007 foi o PMDB e o PT (ambos com 30). Outra explicação é que esses "picos" no gráfico podem ter ocorrido devido a mudanças no legislativo, resultado do começo de uma nova legislatura. 0 gráfico 3 apresenta a quantidade de PECs promulgadas no período analisado.

$\mathrm{O}$ ano que apresentou a maior quantidade de PECS promulgadas foi 2014 com um total de 8 PECs transformadas em norma jurídica. A média do período analisado foi de 3,2 propostas de emendas constitu- 


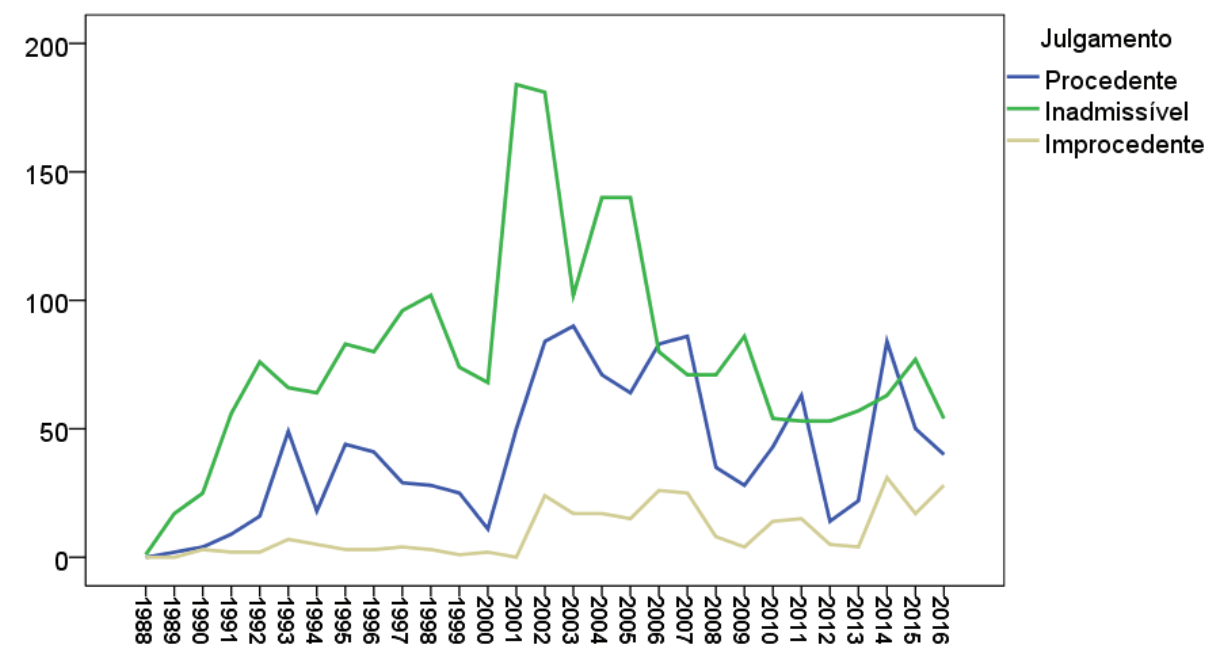

Fonte: Elaborado pelo próprio autor (2017)

cionais transformadas em norma jurídica por ano. 0 gráfico 4 apresenta os partidos que mais tiveram parlamentares com mais propostas de emenda à constituição no período analisado.

De acordo com o gráfico 4, os partidos dos parlamentares que mais apresentaram propostas de emenda à constituição foram o PMDB, PSDB e PT. Esses três partidos também são os partidos com mais parlamentares, o que justifica a grande quantidade de PECs. A média de propostas por partido é de 78 . Alguns partidos ao longo do tempo mudaram o nome, como o PFL que virou DEM e outros foram extintos, como o PPB. Com isso, alguns partidos podem ter apresentado mais PECs se esse fator for levado em conta. $O$ gráfico 5 apresenta as propostas de PEC pelo poder executivo no período.

De acordo com o gráfico, o ano em que o executivo apresentou mais propostas de emenda à constitui- ção foi 1995 (16). 2009 foi o ano em que menos PECs foram apresentadas pelo poder executivo. A média do período foi de 4 propostas por ano. 0 Gráfico 6 apresenta as Ações Diretas de Inconstitucionalidade julgadas no período por resultado do julgamento.

O gráfico 6 mostra as Ações Diretas de Inconstitucionalidade julgadas no período analisado. As ADIs julgadas improcedentes são as que tiveram o pedido julgado improcedente, inadmissível foram as extintas sem julgamento de mérito e as Procedentes foram as Ações Diretas de Inconstitucionalidade cujo pedido foi julgado integral ou parcialmente procedente. De acordo com os resultados, o ano em que mais ADIs foram julgadas foi 2002, com 24 ADIs julgadas improcedentes, 181 Inadmissíveis e 84 procedentes. Das 5545 Ações Diretas de Inconstitucionalidade apresentadas no período, $1183(21,3 \%)$ foram julgadas procedentes e $1803(32,5 \%)$ aguardam julgamento. 0 gráfico 7 apresenta a quantidade de ADIs ajuizadas por autor. 


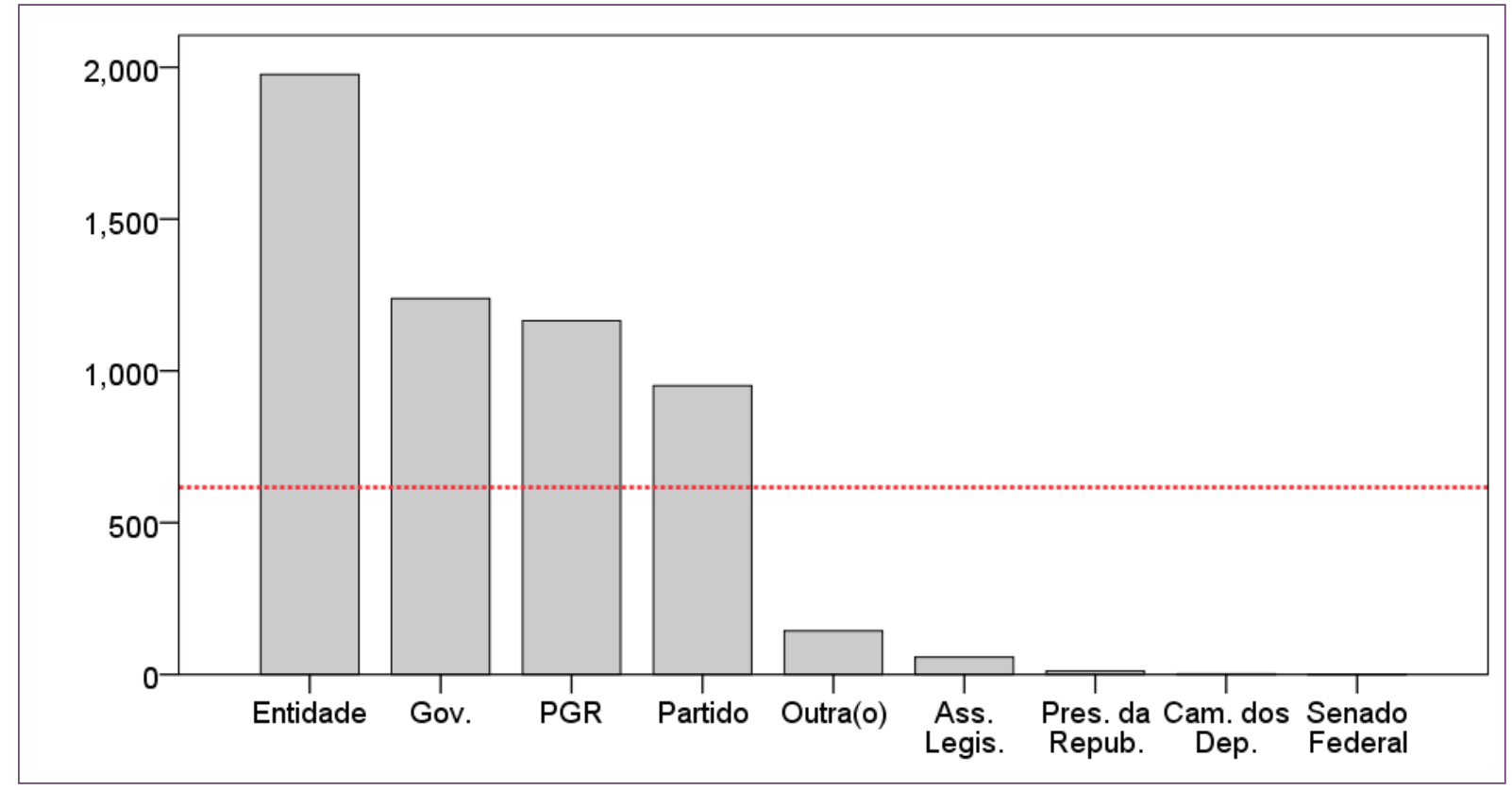

Fonte: Elaborado pelo próprio autor (2017)

Gráfico 8. Quantidade de ADIs julgadas procedentes por autor (1988-2016)

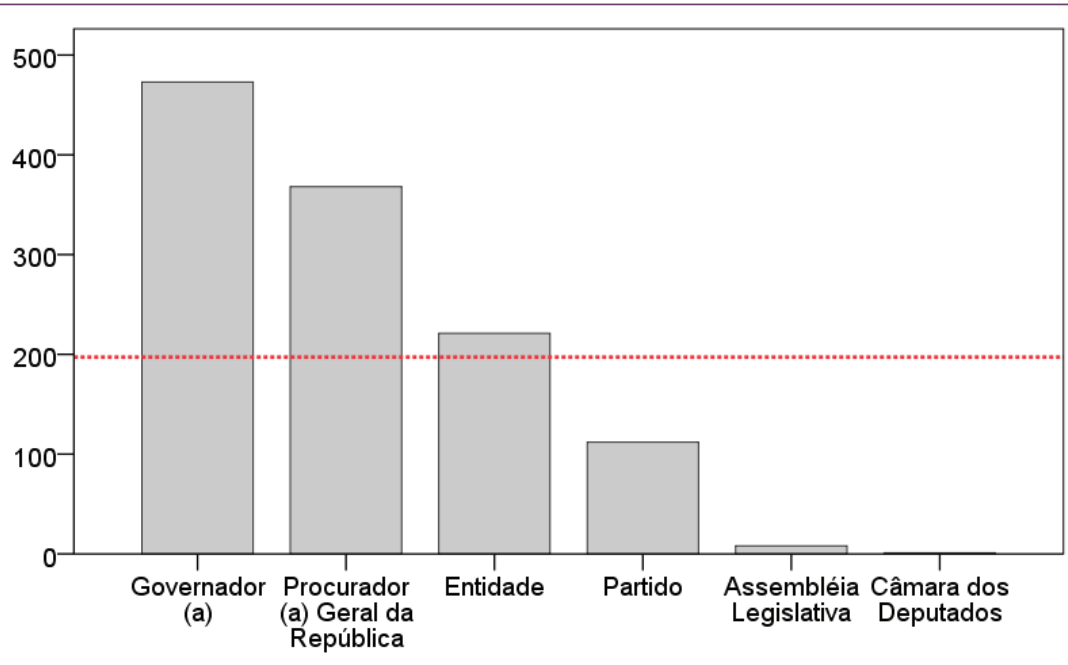

Fonte: Elaborado pelo próprio autor (2017)

De acordo com o gráfico 7, quem mais apresentou Ações Diretas de Inconstitucionalidade foram as entidades (sindicatos, associações, etc.) seguidas dos governadores. A média no período foi de 616 . 0 gráfico abaixo apresenta a quantidade de ADIs que foram julgadas procedentes por autor.

O gráfico 8 mostra a quantidade de Ações Diretas de
Inconstitucionalidade declaradas procedentes por autor. Os governadores foram quem mais obtiveram ADIs procedentes, com 473, seguido da Procuradoria Geral da República (PGR), com 368. A média de ADIs por autor julgadas procedentes é de 197.

Em uma análise pormenorizada das Ações Diretas de Inconstitucionalidade no período de 1988 a 2012, 


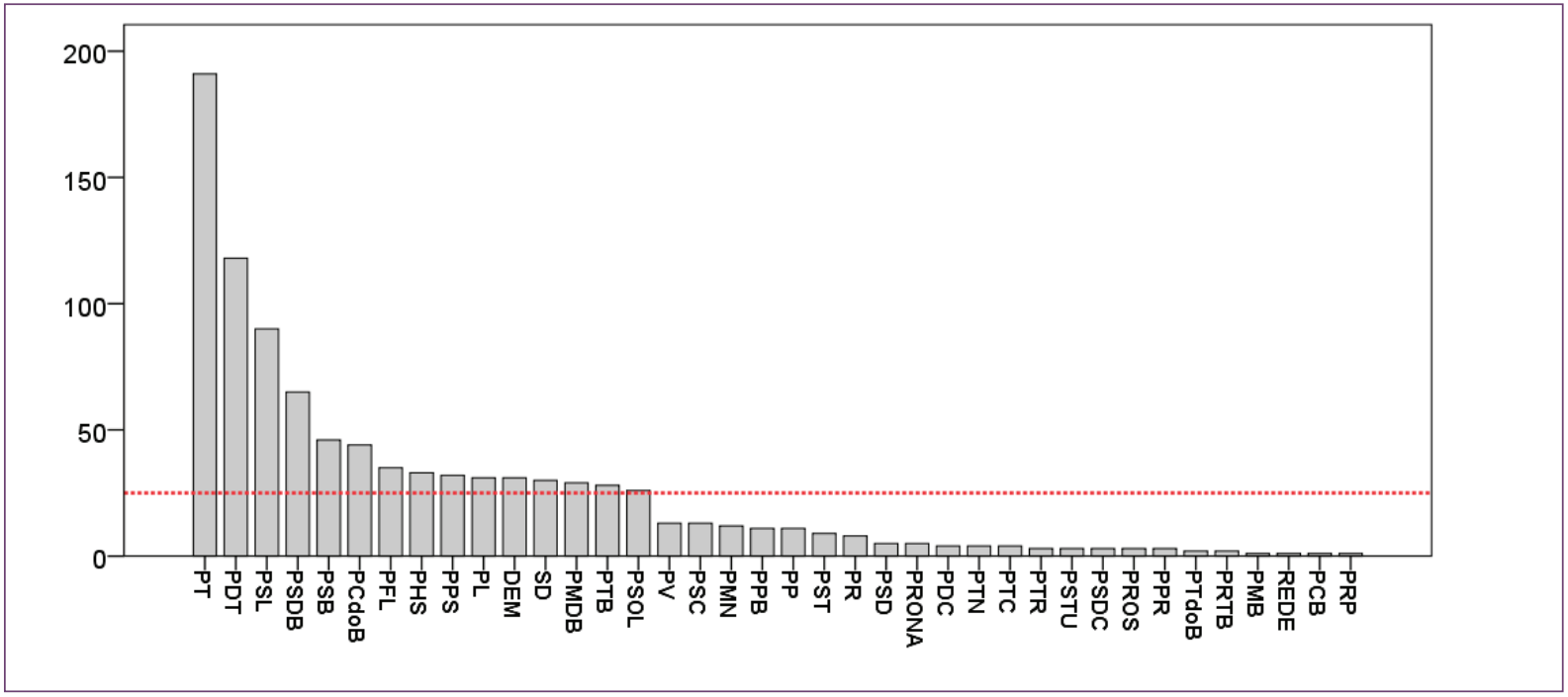

Fonte: Elaborado pelo próprio autor (2017)

Costa e Benvindo (2014) apontam que em relação aos governadores, as ADIs resultam normalmente de conflitos políticos entre os governadores e as assembleias legislativas. Já em relação a PGR, os autores verificam um grande número de processos relacionados a definição das atribuições dos ministérios públicos dos estados, com uma atuação abaixo da média em relação aos argumentos de direitos fundamentais (COSTA E BENVINDO, 2014) ${ }^{9}$. Em suma, de acordo com os autores:

O perfil geral das decisões e dos atores mostra que a combinação do perfil político dos legitimados com a jurisprudência restritiva do STF em termos de legitimidade conduziu a um modelo de controle concentrado que privilegia a garantia dos interesses institucionais ou corporativos. Apesar dos discursos de legitimação do controle concentrado normalmente se justificarem na necessidade de oferecer proteção adequada aos direitos dos cidadãos, o que se observa na prática é uma garantia relativamente efetiva dos interesses corporativos e não do interesse público. E mesmo quando o in-

9 Apesar disso, os autores pontuam que o Ministério Público é o único autor sem "limitação da pertinência temática cujo êxito na defesa dos direitos fundamentais não foi preponderantemente ligada a interesses corporativos (como no caso dos partidos políticos) ou a interesses de grupos de pressão (como no caso da OAB). (COSTA E BENVINDO, p. 76, 2008) teresse público é efetivamente garantido por decisões em ADI baseadas na aplicação de direitos fundamentais, quase sempre peço MP ou pelos governadores, a maior parte das intervenções é no sentido de anular benefícios concedidos de forma indevida, e não de garantir direitos individuais, coletivos e difusos, que têm uma participação minoritária. (COSTA E BENVINDO, p.77, 2014)

O gráfico 9 mostra a quantidade de ADIs por partido. De acordo com o gráfico, o partido que mais apresentou ADIs ao STF foi o PT, seguido do PDT e do PSL. A média no período é de 25 Ações Diretas de Inconstitucionalidade por partido. Conforme Costa e Benvindo (2014), a maioria das decisões exitosas em relação aos partidos políticos estão relacionadas a interesses institucionais e conveniências político-eleitorais (como criação e nomeação de cargos e normas de direito eleitoral).

\section{Conclusão}

O propósito deste artigo foi apresentar de maneira descritiva uma análise referente às Ações Diretas de Inconstitucionalidade e Propostas de Emenda à Constituição. Apesar da rigidez constitucional pontuada em relação à Constituição Brasileira, a sua extensão e detalhamento bem como outros fatores levam a um alto grau de emendamento. Percebe-se que 1995 
foi o ano com mais PECs apresentadas e transformadas em norma, bem como um aumento substancial de Propostas de Emenda à Constituição no começo de cada governo. Verifica-se também que os partidos que mais tiveram parlamentares apresentando PECs foram o PMDB, PSDB e PT.

No que se refere às Ações Diretas de Inconstitucionalidade, 2003 foi o ano com mais ADIs ajuizadas, enquanto que 2002 foi o ano com maior quantidade de julgamentos. Quem mais apresentou ADIs no período foram as entidades e quem mais obteve ADIs julgadas procedentes foram os governadores. Partidos pequenos como PCdoB, PSOL e PPS estão na média dos partidos que mais apresentaram ADIs. De acordo com Costa e Benvindo (2014), isso pode ser resultado do uso das ADIs como um instrumento de retórica política, buscando com a judicialização um certo grau de visibilidade.

Espera-se que, por meio da visualização descritiva destes instrumentos, seja possível uma análise inferencial futura das ADIs e PECs de maneira conjunta. Algumas questões podem ser levantadas por meio deste trabalho, como por exemplo, das ADIs que foram julgadas procedentes, quantas levaram a uma nova interpretação da norma constitucional?

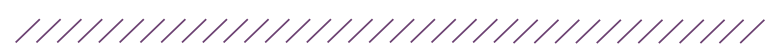

\section{Referências}

Akerman, William. Ação direta de Inconstitucionalidade: principais aspectos. (2012) Revista Jus Navigandi. Disponível: <https://jus.com.br/artigos/20894>.

do Brasil, S. F. (1988). Constituição da república Federativa do Brasil. Brasília, Senado Federal.

Brandão, Rodrigo. Rigidez constitucional e pluralismo político. Revista Brasileira de Direitos Fundamentais e Justiça, n. 5, p. 86-125, 2008.

Costa, A., \& Benvindo, J. Z. (2014). A Quem Interessa o Controle Concentrado De Constitucionalidade?: O Descompasso entre Teoria e Prática na Defesa dos Direitos Fundamentais. Working Paper, 2014 (SSRN). Disponível em: http://www.ufjf. br/siddharta_legale/files/2014/07/Alexandra-Costa-e-Juliano-Zaiden-a-quem interessa-o-controle.pdf

Couto, C. G., \& Arantes, R. B. (2006). Constituição, governo e democracia no Brasil. Revista Brasileira de Ciências Sociais, 21(61), 41-62.

Elster, J. (2009). Ulisses liberto: estudos sobre racionalidade, pré-compromisso e restrições. São Paulo: Editora UNESP.

Mariano, J. S., 2017, "Jurisdição constitucional no Brasil (1988-2016)”, doi:10.7910/DVN/LIHOFS, Harvard Data Verse.

King, G. (1995). Replication, replication. PS: Political Science \& Politics, 28(3), 444-452.

Mascarenhas, P.. Manual de Direito Constitucional. [S.l.: s.n.], 2008.

Melo, M. A. (2013). Mudança constitucional no Brasil, dos debates sobre regras de emendamento na constituinte à "megapolítica". Novos Estudos-CEBRAP, (97), 187-206.

Melo, M. A. (2007). Hiperconstitucionalização e qualidade da democracia: mito e realidade. A Democracia Brasileira: Balanço e Perspectivas para o Século XXI. Belo Horizonte, UFMG/Humanitas, 237265.

De Moraes, A. (2005). Direito constitucional. Ed. Atlas. Negretto, G. L. (2012). Replacing and amending constitutions: The logic of constitutional change in Latin America. Law \& Society Review, 46(4), 749-779.

Noronha, L. N. T. (2011). Processo legislativo e emendamento constitucional no Brasil pós-1988 (Dissertação de Mestrado, Universidade de São Paulo). 
Oliveira, F. M. H. R.; Mota, I. F. X. et al. (2005). Mutação Constitucional. Revista Jus Navigandi. Disponível: $<$ https://jus.com.br/artigos/7433>

Tavares, A. (2012). Curso de direito constitucional (10a. ed.). Editora Saraiva.

Data de submissão/Submission date: 11.12.2017.

Data de aceitação para publicação/Acceptance date: 10.08.2018 